\section{A violência nas relações de conjugalidade: invisibilidade e banalização da violência sexual?}

\author{
Violence in conjugal relations: \\ concealing and taking sexual violence for granted
}

\begin{abstract}
1 Escola Nacional de Saúde Pública, Fundação Oswaldo Cruz, Rio de Janeiro, Brasil.

Correspondência S. M. Dantas-Berger Núcleo de Gênero e Saúde, Departamento de Ciências Sociais, Escola Nacional de Saúde Pública, Fundação Oswaldo Cruz. Rua Leopoldo Bulhões 1480, Rio de Janeiro, $R J$ 21041-210, Brasil. rsberger@ar.microlink.com.br sdantas@ensp.fiocruz.br
\end{abstract}

\begin{abstract}
This article presents the results of a qualitative study of women who had filed complaints of domestic violence, situating gender relations in a broader context. The authors focus on the meaning ascribed to sexual coercion in violent relations, suggesting that conjugal sexual violence is related to the perverse effects of changes in the sexual division of labor and the aggravated double demands on women from housework and the workplace, in relation to the dismantling of the male's role as provider in situations of poverty. In this context, women's refusal to engage in sex (a form of resistance which expresses their desire to be sexual protagonists and communicates disappointment with their partners) can be seen as contributing to the exacerbation of conjugal violence. In their partial position of "subjects of resistance", these women reveal a situation of oppression which is rarely referred to as violence: feelings of disgust and repulsion following sexual relations conceded as "conjugal rights" are similar to those manifested by victims of rape by strangers (which, in contrast, is generally recognized as "sexual violence").
\end{abstract}

Spouse Abuse; Women's Health; Domestic Violence
Sônia Maria Dantas-Berger 1

Karen Giffin 1

\section{Introdução}

Este artigo apresenta resultados parciais de um estudo qualitativo, com enfoque relacional-estrutural de gênero, sobre percepções e vivências femininas relacionadas à violência sexual, tanto no âmbito público (estupro por homem desconhecido) como privado (em relações conjugais) 1 .

Foram entrevistadas nove mulheres que denunciaram violência conjugal, atendidas no Centro Integrado de Atendimento à Mulher (CIAM) do Conselho Estadual da Mulher do Rio de Janeiro, referência na atenção psicossocial e jurídica a casos de violência e discriminação contra mulheres. Em um hospital público, foram entrevistadas três vítimas de estupro por desconhecido.

Enquanto estudos baseados em entrevistas com mulheres estão revelando que a violência sexual é comum, há uma relativa "invisibilidade" desta violência nas denúncias de violências praticadas por homens contra mulheres no âmbito doméstico. A proposta deste artigo é discutir como as relações sexuais acontecem e qual lugar ocupam nas relações de conjugalidade violentas, destacando a ocorrência e os sentidos atribuídos ao "sexo cedido" e/ou obrigado por mulheres que denunciaram agressões físicas e psicológicas de seus parceiros.

A compreensão da violência contra mulheres ganha mais sentido ao adotarmos uma aná- 
lise que considere as condições em que histórica e socialmente se constróem e estabelecem as relações sociais de sexo, ou seja, quando analisada sob a perspectiva de gênero. Aqui, buscou-se compreender em que medida estereótipos de gênero, aliados às condições materiais de sobrevivência, banalizariam ou impediriam uma maior visibilidade do fenômeno da violência sexual conjugal.

Contudo, considerando-se a complexidade do fenômeno da violência contra mulheres e o lugar que ocupa numa rede de violência maior ou estrutural, não se pode perder de vista sua interseção com outros fatores determinantes, "gramáticas sociais" ou "sistemas de mediação social”, como classe social, raça/etnia, as leis e representações sociais, entre outros 2,3,4.

Sendo assim, entende-se que este tipo de violência não será igualmente percebido ou vivido por toda mulher, ou seja, gênero se conjugará com outros elementos como idade, condições familiares, sociais, econômicas e culturais, sem existir um caráter universalizante, mas, sim, socialmente estruturado no modo como esses elementos se associam ou não em suas vidas.

A delimitação conceitual do problema da violência contra mulheres implica enfrentar uma espécie de "ambigüidade terminológica", um não-consenso sobre o modo mais apropriado de nomear os variados tipos de violência física, emocional e sexual 3,5,6,7,8.

Embora a violência que se baseia em gênero seja mais abrangente, já que "vitima" tanto mulheres como crianças e adolescentes de ambos os sexos, muitas vezes, violência "contra mulheres" e violência "de gênero" ou "baseada em gênero" aparecem como sinônimos ou termos intercambiáveis 4,6 .

Neste bojo, por serem as violências de homens contra mulheres e meninas mais freqüentemente retratadas ou observadas no âmbito das relações familiares e/ou íntimos, os termos "violência doméstica" e "violência intrafamiliar" são outras possibilidades terminológicas, embora não se restrinjam à violência contra as mulheres.

A Conferência de Direitos Humanos de 1993 gerou uma definição oficial das Nações Unidas sobre a violência contra a mulher: "todo ato de violência de gênero que resulte em, ou possa resultar em dano ou sofrimento físico, sexual ou psicológico da mulher, incluindo a ameaça de tais atos, a coerção ou a privação arbitrária da liberdade, tanto na vida pública como na vida privada" 5 (p. 3).

O que enfatizamos aqui na articulação entre violência masculina e gênero feminino é a condição de ser “alta sua incidência e severidade quando comparada com a violência praticada por mulheres contra homens" 9 (p. 21). No entanto, numa visão relacional dos gêneros, não se pode ignorar nem o fato das violências que atingem homens na esfera pública também serem relacionadas aos papéis e ideologias de gênero masculinos, nem as possíveis conseqüências destas violências públicas para as relações íntimas entre os gêneros.

\section{A ordem patriarcal e a transição de gênero: os gêneros na história e a visibilidade da violência sexual}

Uma ordem social de tradição patriarcal por muito tempo "consentiu" num certo padrão de violência contra mulheres, designando ao homem o papel "ativo" na relação social e sexual entre os sexos, ao mesmo tempo em que restringiu a sexualidade feminina à passividade $\mathrm{e}$ à reprodução. Com o domínio econômico do homem enquanto provedor, a dependência financeira feminina parecia explicar a aceitação de seus "deveres conjugais", que incluíram o "serviço sexual".

O controle cotidiano da sexualidade feminina nas sociedades de tradição patriarcal acompanhou a ascensão da ideologia da família nuclear, que passou a funcionar como um dos principais meios de organizar as relações sexuais entre os gêneros. Algumas teóricas feministas apontaram uma associação direta entre a sexualidade e a situação de opressão e desigualdade: “a objetificação sexual é o processo primário de sujeição das mulheres" 10 (p. 517); o controle da sexualidade é "o método por excelência do controle cotidiano das mentes e corpos das mulheres nas culturas patriarcais" 11 (p. 165).

Este foi um dos campos prioritários de luta dos movimentos feministas e dos estudos de gênero desde a década de 60 , ao chamarem a atenção sobre o quanto o que é da ordem privada da família é operado no social: "o pessoal, é político".

Nos últimos trinta anos, assistimos à crescente participação de mulheres no trabalho remunerado e no orçamento familiar, junto com uma aceitação social da atividade sexual feminina não-reprodutiva e fora do casamento. A representação ideológica destas mudanças em termos positivos, na celebração da "nova mulher" que deve trabalhar fora para ser "independente", controlar sua fecundidade e ser ativa sexualmente, indica que estamos perante uma "transição de gênero" 12.

Embora esta relativização da tradicional divisão sexual do trabalho e do controle sexual in- 
dique que o patriarcado não é mais o mesmo, seu efeito sobre as mulheres não é homogêneo. Para muitas mulheres no Brasil, a necessidade da sua presença no mercado de trabalho acompanha o aprofundamento da pobreza e da "dupla jornada”. Tendo, agora, responsabilidades não somente na esfera doméstica, mas também na provisão material da família, vivem uma atualização das desigualdades de gênero. Como caracterizar tais mudanças na sexualidade?

Em seu estudo histórico sobre a construção do estupro como fenômeno social na França desde o século XVI, Vigarello 13 associa a visibilidade contemporânea das diversas categorias de violência sexual ao imperceptível nascimento de uma nova visão do sujeito e da intimidade. A mudança na percepção da violência sexual contra mulheres, ao passar a ser visto como crime, focaliza e valoriza atos até então desprezados: "uma massa de gestos transgressores se impõe ao olhar, não porque sejam novos, mas porque são observados de outro modo" 13 (p. 225). Necessariamente, este outro modo de olhar implica uma mudança na relação social entre homens e mulheres e na abordagem da situação da violência sexual, onde a mulher busca sustentar, ainda que de forma ambivalente, uma posição de Sujeito (e não de objeto) nas relações sexuais que vivencia.

Bozon 14, em estudo com homens e mulheres na França contemporânea, considera as práticas e as concepções da sexualidade e da conjugalidade como "indicadores" do estado atual das relações sociais de sexo. Conclui que, apesar da transformação recente nas atividades das mulheres na esfera pública, nas normas e até mesmo nas práticas sexuais de mulheres e homens, mantém-se diferenças substanciais em suas visões das relações sociais de sexualidade. Enquanto as mulheres aspiram a serem sujeitos sexuais e praticam sexo fora do casamento, elas preferem a sexualidade contextualizada no âmbito de uma relação de afeto e compromisso, iniciando processos de separação quando não estão satisfeitas com as relações. Ao mesmo tempo, "nas representações masculinas, a mulher continua a ser considerada como um objeto que se deseja adquirir (e depois exibir), mais do que como um sujeito como qual se estabelece uma relação" 14 (p. 127).

Este estudo indica que a maior presença na esfera pública e no trabalho remunerado não tem garantido a estas mulheres as relações afetivo-sexuais que elas desejam, confirmando a importância de uma ótica relacional nas questões de gênero. Aponta para uma certa lentidão do tempo de gênero, mais especificamente, do gênero masculino. Pode este descompasso en- tre os tempos de gênero feminino e masculino estar produzindo ou potencializando conflitos nas relações sociais de sexualidade?

\section{Estudos empíricos}

Tanto no estudo pioneiro de Heise et al. 5, que reuniu dados de 35 estudos em 24 países, como no World Report on Violence and Health 15 , está comprovada estatisticamente a alta incidência de violência de homens contra mulheres, sendo a forma mais endêmica a violência sexual e física de companheiros íntimos contra suas mulheres, o que conforma um importante problema de saúde pública. Em 48 pesquisas de base populacional, $10-69 \%$ das mulheres entrevistadas apontaram terem sido alguma vez alvo de agressão física de seus parceiros; a violência física é freqüentemente acompanhada da violência psicológica e, em um terço a $50 \%$ dos casos, pela violência sexual.

No Brasil, desde os anos 80, vários estudos abordam a questão da violência doméstica e conjugal, com base no trabalho das instituições policiais e jurídicas, principalmente através das Delegacias Especializadas no Atendimento às Mulheres (DEAMs). Grande parte destes trabalhos foi fortemente influenciada pelo movimento de mulheres, que privilegiou o direito da mulher à sua segurança na "privacidade" do lar, e estimulou as denúncias contra os maridos agressores.

No entanto, a carência de estudos populacionais sobre a violência baseada em gênero no país, bem como de pesquisas operacionais nos serviços, acaba por impossibilitar um melhor conhecimento sobre este fenômeno e suas conseqüências em saúde. Este tipo de violência ainda é pouco investigado pelos profissionais de saúde, o que deve colaborar para que seja subestimado em dados oficiais 16,17.

As estatísticas mais recentes, de 267 DEAMs, identificaram os crimes mais denunciados pelas mulheres. Entre 326.693 notificações recebidas, havia 113.727 queixas de lesão corporal, 107.999 de ameaças e 32.183 para vias de fato. Logo depois, encontramos os crimes contra a honra: 13 mil de injúria; 10.049 de difamação; e 6.805 para calúnia. Especificamente para o crime de estupro, foram totalizadas 4.697 queixas em todas as DEAMs do país 18.

Indubitavelmente, a maioria esmagadora dos dados aponta para a maior ocorrência e/ou visibilidade das violências físicas, tipificadas criminalmente por lesões corporais, seguidas pelas violências psicológicas, principalmente ameaça, difamação e injúria. A violência sexual, 
especialmente a coerção e/ou violência sexual praticada por parceiro íntimo no âmbito privado, está pouco evidenciada ou inexistente nas estatísticas disponíveis: "é praticamente impossível desvendar, nos dados estatísticos, situações de estupro conjugal, porque elas estão escondidas em outros itens, como o de lesões corporais" 19 (p. 48).

Principalmente a partir da segunda metade dos anos 90, existe consenso quanto à carência de dados apropriados sobre a violências sexual contra mulheres no Brasil, e sobre a necessidade de serem realizadas investigações quantitativas e qualitativas que colaborem para a compreensão do problema 9,20,21.

No campo da violência sexual doméstica, a associação entre lares violentos e estupro conjugal vem sendo detectada, mais consistentemente, em estudos internacionais. Entre os principais resultados de um estudo nacional pioneiro de sobre a violência doméstica e sexual 22, baseado em 3.193 entrevistas com usuárias de 19 serviços de saúde, encontramos: " $40 \%$ das mulheres entrevistadas declararam violência física - exclusiva ou conjugada com a forma sexual - cometida pelo parceiro atual ou anterior; 5\% relataram casos exclusivos de violência sexual. A violência sexual, portanto, ocorre sobretudo associada à violência física" 22 (p. 2).

Sendo a violência sexual associada à violência física dos parceiros nos casos de violência conjugal, qual o lugar ocupado pela sexualidade nestas relações? Existiria a queixa de "estupro marital" entre mulheres que viveram a situação de violência conjugal? Quais elementos ou conteúdos poderiam ser relevantes para que elas identifiquem, nomeiem ou dêem visibilidade às agressões sexuais que vivem dentro do casamento? Quais seriam os efeitos ou conseqüências deste tipo violência, especialmente em termos da saúde e da sexualidade femininas? Estas são algumas questões que orientaram o estudo e que ora trataremos de apresentar.

\section{Material e métodos}

No CIAM foram realizadas e gravadas, com consentimento oral e escrito, em consonância com a Resolução 196/96 do Conselho Nacional de Saúde, um total de nove entrevistas semi-estruturadas com mulheres entre 25 a 51 anos que efetivaram queixas de violência conjugal, mas sem necessariamente relatarem coerção e/ou violência sexual. Estes dados foram complementados por análise de dados próprios do serviço, observação de rotinas de atendimento e entrevistas com informantes-chaves.
Quatro mulheres possuíam escolaridade de nível fundamental incompleto; quatro nível médio (sendo duas incompletos); e uma de nível superior. Seis foram registradas no serviço como brancas e três como pardas. O tempo de relacionamento variou entre 6 e 22 anos: quatro delas mantinham o relacionamento conjugal entre seis a dez anos, três entre 11 a 15 anos e duas por mais de 20 anos. Uma entrevistada teve 4 filhos e as outras entre 1 e 3 filhos. Duas declararam renda familiar menor que um salário mínimo, duas entre um a dois salários, três entre três a cinco salários, uma de seis salários e outra de vinte. Sete tinham trabalho remunerado, quatro em empregos formais e três informais, uma estava aposentada e outra era "do lar".

Para todos os nove casos, o motivo registrado para a procura do serviço foi a violência de gênero doméstica. Em oito casos, lesão corporal foi denunciada no primeiro atendimento; em cinco destes, houve a associação da lesão corporal com algum outro tipo de violência, incluindo violência psicológica, através de discriminações, intimidações, e/ou ameaça. Uma mulher, em seu primeiro atendimento, registrou a ameaça como tipo exclusivo de violência.

Não encontramos nenhum registro em que a violência sexual houvesse sido notificada em suas fichas de primeiro atendimento. Porém, em atendimentos subseqüentes, algum relato técnico ligado a possíveis situações de violência sexual foi registrado em quatro casos.

Conscientes das possíveis barreiras para o compartilhamento público dessas vivências, apostamos na importância e possibilidade de rompermos com este silêncio naturalizado que parece impedir esta nomeação, tanto em seu âmbito "assistencial" como "político", dificultando qualquer avanço. Neste sentido, buscamos propiciar à mulher, através de uma interação social específica (pesquisadora-pesquisada), meios de elaborar e tornar públicos seus significados da violência, bem como de compartir estas experiências, respaldada por cuidados éticos e técnicos.

\section{Alguns resultados}

Gênero e sexualidade: aprendendo e vivendo estereótipos, desigualdades e impasses

Para muitas das entrevistadas, as expectativas de realização refletiram sua formação familiar para o casamento, a constituição e cuidados com a família: “(...) minha formação, meus pais me colocaram isso: família, casa, para sempre...” (Estela). “(...) E eu sempre tive vontade de 
criar uma família, de ter uma família de poder cuidar de uma casa - da minha casa. (...) Ter uma casa, uma família, continuar trabalhando, progredir, eu sempre pensei assim..." (Moema).

Assuntos "sexuais" não foram, ou foram pouco, abordados em casa. Amigas, profissionais ou serviços de saúde, a escola e o trabalho, colaboraram de alguma forma, na formação/orientação destas mulheres: "então eu fui sendo criada assim, eu não tive orientação nenhuma. A minha família não tem diálogo (...) Isso tudo eu fui descobrindo na escola, né? Aí, depois, vêm as amigas que ensinam..." (Moema).

Com pouca orientação familiar e expressões pouco afirmativas da sua sexualidade, mas com a busca de felicidade e progresso na vida através do casamento e/ou da maternidade, foram morar com seus maridos e parceiros em diferentes arranjos conjugais, sem necessariamente se sentirem prontas para o relacionamento a dois.

Contudo, além de não se virem correspondidas nas suas expectativas de progresso a partir do enlace matrimonial, se viram comprometidas e solitárias, tanto nas funções tradicionalmente femininas de "gestão doméstica e afetiva" 23, como também no sustento econômico familiar. Muitas apontaram uma falta de ambição e/ou de vontade de progredir de parceiros, alguns em situação crônica de desemprego: " $e$ o que ele sabe fazer é brigar, é fazer as agressões, é quebrar as coisas. Ele não ajuda em nada em casa, a assistência, os alimento são eu que compro, e, as coisas dentro de casa, alguma coisa que eu tenho, foi através do meu trabalho" (Suzi).

“(...) Porque se meu marido tivesse sabido retribuir todo esse amor, junto comigo (...) pelo menos uma parte do que eu faço pra ele, seria a coisa mais linda, mais importante da minha vida... Ser feliz com ele. (...) Ele nunca foi um pai companheiro, de sair com elas, de fazer passeio, de levar elas no médico junto comigo... Sempre só fui eu..." (Elaine).

"Ele acha que o que ele coloca dentro de casa é o suficiente e não é. [Ela fala para parceiro] Então você tem que trabalhar porque a gente tem um filho (...) Melhorar a casa, fazer mais cômodos - a gente já tem um quarto e para fazer um quartinho dele [filho] lá... Assim, progredir (...) minha casa é de telha, então nunca tivemos uma oportunidade de botar uma laje. Quer dizer, se ele trabalhasse, dava para... se ele pensasse em progredir..." (Moema).

Conflitos, violência e vida conjugal: queixas e resistências femininas e masculinas

A imagem da mulher virtuosa - que todo homem gostaria de "ter" - apareceu algumas ve- zes, em contrapartida à imagem do homem que falha: “..é o que as pessoas falam: 'muitos homens gostariam de ter uma esposa igual a você, que é uma mulher que trabalha, que se dedica à casa, se dedica ao trabalho, não te vê na porta de bar, não te vê conversando com homem nenhum' - é muito difícil eu conversar com homem, eu tenho muita amizade com senhoras..." (Moema).

Observamos que quanto mais as parceiras pareceram cobrar ou querer dos maridos o que eles "deveriam dar", segundo o padrão tradicional, como provedores, mais o conflito e as agressões entre o casal se acentuava. Para eles, em casa como na rua, a atuação feminina parecia revelar seu próprio "desvalor": "e ele fica revoltado porque ele vê que eu com pouca dificuldade ou muita dificuldade, eu consigo honrar meu nome - é coisa que eu mais tenho amor é a meu nome limpo, - e ele, realmente, ele não tem nome limpo... E ele desconta tudo em cima de mim: fica uma pessoa insegura, frustrada, não é capaz de nada, né? Não tem vontade de ir à frente (...). Ele é super-revoltado com isso... E isso é a maneira que ele tem para destruir o que eu tenho..." (Suzi).

Em paralelo, expressaram descontentamento em se sentirem tratadas como objetos ou seres sem autonomia, e sua resistência foi um motivo para brigas. Nas entrevistas, manifestaram suas aspirações a participarem mais livremente do mundo público, mas quanto mais romperam com padrões femininos tradicionais de domesticidade e passividade, mais o conflito conjugal se radicalizava: “...ele nunca aceitou este meu jeito. Ele acha eu tinha que ser só dele, e não conversar com ninguém... Pra ele se eu não conversasse com ninguém, era uma boa. [Você aceita isso?] Não porque eu preciso de todo mundo. Tenho dois filhos (...) então eu não posso me virar contra as pessoas, por causa dele... Ele não vai deixar de trabalhar para ficar com as crianças em casa (...) Ele não aceita, ele acha que eu tenho que ser sozinha pra depender só dele, entendeu? Ficar a seu dispor..." (Geisa).

\section{Qualificando as agressões e violências}

Entre as agressões nomeadas, predominou a violência física. No entanto, as agressões cotidianas ligadas ao sofrimento emocional, afetivo e moral, violência que denominaremos como "psicológica", foram recorrentes e freqüentemente consideradas as piores: "ele só sabe, é agredir, machucar.. Não precisa de uma arma pra te atacar: ele desmoraliza (...) não precisa nem usar a mão, (...) te difamando, eu acho que é a coisa pior que existe!" (Gal). 
A intimidação não só por força física, mas pela força psicológica ou coerção, a opressão e dominação pelo medo e culpabilização, foram sendo desveladas: “(...) Eu não fico com raiva em uma briga não, mas eu fico com medo... (...) Realmente, eu tinha medo de que ele fizesse alguma coisa comigo: eu esperava às vezes, ele dormir, e eu, ali no sofá, ou fico assim na cama, aí eu adormecia. Mas, não apagava, qualquer barulhinho que eu escutasse - ou ele mesmo se mexendo, se eu escutasse - eu abria o olho, e ficava ali quietinha..." (Moema).

A maioria respondeu que reagia frente às agressões, mais especificamente frente à violência física, sempre com a intenção de se defenderem ou evitarem a violência. Vale ressaltar que os relatos de violência física e atentados contra suas vidas foram mais freqüentes no caso dos maridos do que no caso dos estupros cruentos 1 .

\section{O sexo na conjugalidade violenta}

A degradação crescente da relação se refletiu igualmente na qualidade das relações sexuais, transformando a cama num campo de batalha, revelador, em alguns casos, do desprazer sexual cronificado. Para a maioria, o sexo foi um dos motivos mais freqüentes para que a violência se instalasse.

Segundo os relatos, a relação sexual ocorreu, muitas vezes, sob forma de coerção "naturalizada" ou como "cláusula" prevista no contexto das obrigações conjugais. Todas relataram alguma situação do parceiro querer e insistir na transa apesar dela não querer; nenhuma delas fez uma denúncia prévia desta situação nos serviços que buscaram. O sexo cedido ou sob resistência foi recorrente, mas pouco nomeado como violência.

De modo geral, apesar de tentarem "resistir" - dizerem não - acabavam "cedendo" à relação sexual, algumas vezes por temerem a agressão física, a perda de apoio financeiro ou acusações de infidelidade: "então, quando ele bebe, ele não deixa eu dormir, ele tenta fazer sexo comigo à força... Se eu não fizer, ele não deixa eu dormir, entendeu? Então - [Entrevistadora questiona: o que você faz?] - eu, o único jeito é fazer, né, que é para eu poder ter sossego, eu poder dormir e poder ter paz, porque senão eu não tenho... Se eu não deixar ele fazer, aí ele começa a querer me bater, me agredir, me esculhambar.. Dizer que eu estou com homem na rua... Que eu tenho macho na rua." (Geisa). "[Quando ela nega o sexo, ele diz] Você é minha mulher, está aqui pra que? Ele pega, me deita na cama, à força(...). Eu deixo, não tem como! [Se ela resiste, ele fala] Ah! É, né? Sua puta, piranha, safada! Você não quer transar comigo porque tu 'fode' com os outros..." (Elaine).

A violência física, de fato, exacerbou-se em alguns casos quando negaram o sexo como obrigação conjugal: “..eu comecei a me reservar tanto, que chegou ao ponto de eu notar que a agressão aos filhos, a mim, era por causa disso, entendeu?" (Zilka).

Destacamos que o "consentimento" ao sexo não desejado foi relativo para algumas mulheres, visto que, manifestaram nojo e repulsa similares às reações ao estupro cruento, como encontrado no estudo de Machado 24: "eu me senti imunda, eu me senti imunda, suja, porque juntou a raiva dele me pegar assim, só para satisfazer a vontade dele e não respeitar o que eu estava passando" (Moema).

"Teve uma época que eu fazia sem vontade (...) aí, quando ele virava pro canto e dormia, eu dizia: 'Graças a Deus!' Eu ía pro banho, me lavava toda..." (Mary).

O sexo vaginal forçado no casamento muito poucas vezes foi significado como "violência”, parecendo enquadrar-se socialmente e sexualmente como "normal" na relação. No entanto, concretiza uma situação de opressão para mulheres que consideram o sexo como aspecto de uma relação maior: "eu não consigo nem entender a natureza dele - ele acaba de me bater, de me dar socão, cuspir na minha cara, puxar meus cabelos, aí (...) ele vai dormir, aí depois quando ele acorda, ele vem como se nada tivesse acontecido, vem querer me agarrar a força, me beijar. Aí, eu: 'Pára!' Sai daqui! Eu não sou jumenta...' Que jumento é que acaba de morder a jumenta e, na mesma hora, já tá indo prá cima dela!" (Elaine).

"[Ela diz] Vem cá, você acha que eu tenho capacidade para isso? Você faz o que faz, você me bate, você me humilha, você diz que eu sou isso e aquilo, e aquilo outro, e você acha que eu vou ter cara de pau de chegar e [um ditado popular] 'eu vou me abrir para você?!' Eu não sou mulher de zona não, eu não sou mulher de zona, não, que aceita tudo quanto é coisa e está lá (...) Dizia que não queria. Ah! Porque meu marido, eu sinto que ele é assim, eu sou para ele tipo um objeto, né? Uma coisa que ele comprou, né? Eu acho que não deveria ser assim..." (Zilka).

O sentido de "violência sexual" e/ou do que seria a "pior" violência sexual, esteve associado àquilo que transgride a moralidade - violência moral, objetificação, e para algumas mulheres, o sexo anal. 


\section{Discussão e conclusões}

As expectativas de realização da maioria partiram das representações tradicionais da divisão sexual do trabalho patriarcal: homens na produção/no público e na chefia da casa, mulheres na reprodução/na esfera doméstica, eventualmente "ajudando" no trabalho remunerado.

Entretanto, elas viveram uniões conjugais que exigiram delas funções e responsabilidades na provisão material permanente ou até a chefia da casa, antes responsabilidades preponderantemente associadas aos homens. Embora esta "transição de gênero" 12 seja celebrada como condição principal da "nova mulher" ganhar espaço e autonomia, observamos os efeitos perversos do aprofundamento da dupla jornada feminina. O tradicional controle masculino baseado em seu papel de provedor está em xeque e a resistência de ambos parceiros à sua transição, radicaliza conflitos e colabora para a ocorrência da violência, inclusive sexual, entre o casal.

Nolasco 25 conclui que o homem nesta situação, tendo perdido a base anterior da sua identidade de gênero, mas sem palavras para nomear "o novo", reage com violência. Giddens 26 (p. 92) considera esta situação como relacionada à "derrocada" da ordem patriarcal: "é possível que boa parte da violência que os homens praticam hoje contra a mulher, não seja apenas a persistência do velho sistema, e, sim, uma incapacidade ou recusa de adaptar-se ao novo. Ou seja, não é apenas a continuação do patriarcado tradicional, mas uma reação contra a sua derrocada".

Dessa perspectiva, não podemos entender as relações conjugais sem entendermos as transformações na divisão sexual do trabalho patriarcal no contexto da precarização atual do trabalho. O fenômeno da violência conjugal, situado nas relações interpessoais, é remetido às relações de trabalho, estruturais 4 .

Ao mesmo tempo, as "novas mulheres" que entrevistamos também não mais se adequam às representações tradicionais que colocariam como destino feminino "agüentar" situações de objetificação e violência, para que o casamento (e o seu próprio reconhecimento social como sujeito moral) fosse mantido. São avanços claros, se comparados às pesquisas sobre violência doméstica realizadas há cerca de vinte anos 27.

Retomamos as contribuições de Vigarello 13 sobre a emergência de uma nova visão da mulher como sujeito e a visibilidade da violência sexual e enfatizamos que as aspirações das mulheres de serem sujeitos sexuais estão agora con- textualizadas pelo outro lado da moeda: o desmonte da identidade masculina de provedor.

Nestes novos tempos, as mulheres, além de dizerem que estão "cansadas de sofrer", que "sentem-se usadas" no relacionamento, apontam "falhas" do marido no seu papel de ho$\mathrm{mem} /$ pai-de-família e negam a eles - pelo menos interiormente - a posse do seus corpos.

Assim, recusá-los na cama, dizer não ao sexo não-desejado, pode ser visto como um "contrapoder”, que comunica mágoas e manifesta um protesto frente às desilusões com seus parceiros, numa tentativa de refusar o papel de objeto sexual - sem, no entanto, significar a instauração das mesmas como sujeitos sexuais, que realizam sua própria vontade. Como vimos, o Sujeito sexual representado pelas mulheres em geral, afirmou que a sexualidade insere-se numa relação mais ampla, não podendo ser reduzida a um ato genital. Na sexualidade, alcançaram a posição parcial de "sujeitos do não".

Assim colocado, o ato sexual não consentido não tomou diretamente a conotação de violência no discurso destas mulheres quando denunciaram violências. Porém, alguns aspectos se assemelharam às marcas do estupro cruento: ter nojo da relação, se lavarem imediatamente; perderem ou terem pouco desejo sexual; correrem riscos de uma gravidez indesejada; contraírem infecções sexualmente transmissíveis.

\section{Considerações finais}

Até que ponto diferentes níveis de visibilidade e abordagem da violência sexual - como crime, penalizado social e juridicamente e, como natural no contexto dos contratos conjugais deixam, de certa forma, esvair-se a possibilidade de se nomear e/ou tratar como "estupro" modalidade de violência já incluída na atenção em saúde das mulheres - uma coerção a relações sexuais não desejadas pela mulher?

Reconhecemos que a atuação do setor saúde na trajetória das mulheres em situação de violência conjugal foi limitada em comparação à atenção proporcionada às mulheres entrevistadas que viveram o estupro cruento e procuraram ajuda. A maior parte destas, após buscarem a delegacia, foi encaminhada para um serviço de saúde e atendida dentro do protocolo previsto pelo Ministério da Saúde 28.

Nesse sentido, importantes iniciativas intersetoriais somaram-se para fazer valer direitos das "vítimas", especialmente o direito a interromper uma gravidez decorrente do estupro (conforme previsto, desde 1940, no Código Pe- 
nal Brasileiro). Pouco a pouco, uma atenção mais integral em saúde tem sido normatizada, através da qual, além do aborto legal, o acesso à anticoncepção de emergência e à profilaxia para o HIV são algumas rotinas previstas. No período de 1997 a 2002, o número de serviços habilitados para aplicação do protocolo passou de 17 para 6627 .

Já no que se refere às mulheres em situação de violência doméstica/conjugal, quando encontramos alguma referência relacionada à atenção em saúde que buscaram ou receberam, não avaliamos que tenham sido atendidas dentro de rotinas de atenção sensíveis à abordagem da violência doméstica e sexual 8 . A maior parte dos programas e serviços de saúde não conta ainda com protocolos de atenção para casos de violência doméstica e sexual contra a mulher, apesar de se constatar uma relativa disponibilidade das mulheres, quando entrevistadas, relatarem a situação que vivem 29.

Vale registrar que, mesmo nos casos de estupro cruento, onde a atenção em saúde foi de alguma forma garantida, o fato das mulheres entrevistadas não serem ouvidas ou abordadas - pelo menos nas consultas que relataram ter participado - em suas questões relativas ao seguimento de suas vidas sexuais e afetivas com seus parceiros após o estupro, foi recorrente. Mais uma oportunidade perdida de se acolher, identificar e tratar dos diferentes níveis de vio-

\section{Resumo}

A partir de uma abordagem relacional-estrutural de gênero e sexualidade, este artigo apresenta resultados parciais de um estudo qualitativo com mulheres que denunciaram violência conjugal. Focaliza a ocorrência e os sentidos atribuídos ao fenômeno da coerção sexual marital, apontando para a possibilidade da violência sexual conjugal estar relacionada aos efeitos perversos de transformações na divisão sexual do trabalho e do aprofundamento da dupla jornada feminina quando relacionado ao desmonte da figura de homem provedor em situações de pobreza. Neste contexto, a recusa feminina a sexo - contrapoder que expressa o desejo de ser sujeito sexual e comunica protestos contra as desilusões relacionadas aos parceiros pode colaborar para a exacerbação dos atos violentos masculinos. Na posição parcial de "sujeitos do não", as mulheres revelam ainda uma situação de opressão quase nunca por elas diretamente nomeada como violência: no nojo e repulsa que manifestam contra o sexo cedido como débito conjugal, se assemelham aos sentimentos de vítimas de estupros por desconhecidos - estes sim, de modo geral, mais reconhecidos socialmente como "violência sexual".

Maus-tratos Conjugais; Saúde da Mulher; Violência Doméstica lência e coerção implicados nas vivências femininas da sexualidade?

Abordar a violência contra mulheres e sua interface com a saúde, bem como dar visibilidade à questão da sexualidade e do sexo forçado na conjugalidade implicaria, entre outras tarefas: no reconhecimento da violência como "objeto" do setor saúde, considerando-se tanto a concepção ampliada de saúde como o impacto provocado na qualidade de vida 30 ; na integração de temas como sexualidade, gênero e direitos humanos na prática de equipes multidisciplinares para humanização do atendimento e problematização das situações abordadas; em acolher e fazer interagir demandas femininas e masculinas, buscando-se facilitar tanto uma maior assertividade do Sujeito sexual feminino (para além dos "sujeitos do não") como resgatar a reciprocidade entre os gêneros em tempos de precarização das relações de trabalho e de renegociação de "dívidas conjugais"; na operacionalização interdisciplinar do atendimento em saúde; e, na articulação intersetorial de serviços (Delegacias, Instituto Médico-Legal, Unidades de Saúde, entre outros) que faça valer o direito a uma atenção integral para "vítimas", "autores" de violência e seus familiares, evitando-se a "revitimização" através de uma "rede articulada de assistência médica, psicológica, jurídica, policial e social” 8 (p. 21).

\section{Colaboradores}

S. M. Dantas-Berger elaborou o projeto, participou da redação preliminar e elaborou com K. Giffin o artigo final. K. Giffin participou da redação, edição e revisão do artigo final.

\section{Agradecimentos}

Agradecemos à Fundação Ford e à Secretaria Estadual de Saúde do Rio de Janeiro pelo apoio financeiro ao estudo. 


\section{Referências}

1. Dantas-Berger SM. Violência sexual contra mulheres: entre a (in)visibilidade e a banalização [Dissertação de Mestrado]. Rio de Janeiro: Escola Nacional de Saúde Pública, Fundação Oswaldo Cruz; 2003.

2. Correa S. Gênero e sexualidade como sistemas autônomos: idéias fora do lugar? In: Parker R, Barbosa R, organizadores. Sexualidades brasileiras. Rio de Janeiro: Relume-Dumará; 1996. p. 14959.

3. d'Oliveira AFPL, organizadora. Violência, gênero e saúde. Curso de capacitação para o atendimento a mulheres em situação de violência - coletânea de textos. São Paulo: Departamento de Medicina Preventiva, Faculdade de Medicina, Universidade de São Paulo/Coletivo Feminista Sexualidade e Saúde; 1997.

4. Saffioti H. Contribuições feministas para o estudo da violência de gênero. Labrys, Estudos Feministas $2002 ; 1-2$.

5. Heise L, Pitanguy J, Germain A. Violencia contra la mujer: la carga oculta sobre la salud. Washington DC: Organización Panamericana de la Salud/ Organización Mundial de la Salud; 1994.

6. Soares BM. Mulheres invisíveis: violência conjugal e as novas políticas de segurança. Rio de Janeiro: Civilização Brasileira; 1999.

7. Arcas CC, Ellsberg M. Informe final. Sistematización del proyecto de OPS: hacía un modelo integral de atención para la violencia intrafamiliar en Centroamérica. Washington DC: Organización Panamericana de la Salud; 2001.

8. Oliveira F. Atenção à violência contra a mulher: desafio para profissionais e serviços de saúde. Revista de Atenção Primária à Saúde 2002; 9:1224.

9. Suárez M, Bandeira L. Introdução a violência, gênero e crime no Distrito Federal. In: Suárez M, Bandeira L, organizadores. Violência, gênero e crime no Distrito Federal. Brasília: Paralelo 15/ Editora Unb; 1999. p. 13-26.

10. Mackinnon C. Feminism, marxism, method and state: an agenda for theory. Signs 1982; 7:515-41.

11. Bleier R. Science and gender: a critique of biology and its theories on women. New York: Pergamon Press; 1984.

12. Giffin K. Pobreza, desigualdade e eqüidade em saúde: considerações a partir de uma perspectiva de gênero transversal. Cad Saúde Pública 2002; 18 Suppl:103-12.

13. Vigarello G. História do estupro: violência sexual nos séculos XVI-XX. Rio de Janeiro: Jorge Zahar Editor; 1998.

14. Bozon M. Amor, sexualidade e relações sociais de sexo na França contemporânea. Estudos Feministas 1995; 3:122-35.

15. World Health Organization. World report on violence and health - summary. Geneva: World Health Organization; 2002.

16. Leão EM, Marinho LFB. Saúde das mulheres no Brasil: subsídios para as políticas públicas de saúde. Revista Promoção da Saúde 2002; 6:31-6.

17. Serrano MM. Entrevista. Revista Promoção da Saúde 2002; 6:51-2.
18. Ministério da Justiça. Relatório final da Pesquisa Nacional sobre as Condições de Funcionamento de Delegacias Especializadas no Atendimento às Mulheres. Brasília: Secretaria de Estado de Direitos Humanos, Conselho Nacional de Direitos da Mulher, Secretaria Nacional de Segurança Pública; 2002 .

19. Brazão AT, Grossi MP, organizadoras. Histórias para contar: retrato da violência física e sexual. Natal: Casa Renascer; 2000.

20. Ferreira JD. Estudo de fatores relacionados com a violência sexual contra crianças, adolescentes e mulheres adultas [Tese de Doutorado]. São Paulo: Centro de Referência de Saúde da Mulher e de Nutrição, Alimentação e Desenvolvimento Infantil; 2000.

21. Mello-e-Souza C, Carvalho ML, Galli MB, Alcântara RS, Gaspar F. Violência sexual no Brasil - um diagnóstico da área da saúde, do judiciário e da comunidade. Rio de Janeiro: Ipas Brasil/Fundo das Nações Unidas de População; 2003.

22. Schraiber LB, D'Oliveira AFPL, Falcão MTC. Violência doméstica e sexual entre usuárias dos serviços de saúde. São Paulo: Faculdade de Medicina, Universidade de São Paulo; 2002.

23. Machado LZ, Magalhães MTB. Violência conjugal: os espelhos e as marcas. In: Suárez M, Bandeira L, organizadores. Violência, gênero e crime no Distrito Federal. Brasília: Paralelo 15/Editora UnB; 1999. p. 173-237.

24. Machado LZ. Sexo, estupro e purificação. In: Suárez M, Bandeira L, organizadores. Violência, gênero e crime no Distrito Federal. Brasília: Paralelo 15/Editora UnB; 1999. p. 297-352.

25. Nolasco S. A desconstrução do masculino. Rio de Janeiro: Rocco; 1995.

26. Giddens A. Conversas com Anthony Giddens: o sentido da modernidade. Rio de Janeiro: Editora FGV; 2000 .

27. Machado LZ. Os frágeis direitos da mulher. Revista Promoção da Saúde 2002; 6:22-5.

28. Ministério da Saúde. Prevenção e tratamento dos agravos resultantes da violência sexual contra mulheres e adolescentes - norma técnica. Brasília: Departamento de Gestão de Políticas Estratégicas, Secretaria de Políticas de Saúde, Ministério da Saúde; 1999/2002.

29. Deslandes SF, Gomes R, Silva CMFP. Caracterização dos casos de violência doméstica contra a mulher atendidos em dois hospitais públicos do Rio de Janeiro. Cad Saúde Pública 2000; 16:129-37.

30. Minayo MCS. A difícil e lenta entrada da violência na agenda do setor saúde. Cad Saúde Pública 2004; 20:646-7.

Recebido em 29/Mar/2004

Versão final reapresentada em 17/Ago/2004

Aprovado em 03/Set/2004 